E. stablished in 1969, Universiti Sains Malaysia (USM) now enjoys wide recognition as a leading institution of higher learning. It has 21,744 undergraduate and 5,756 (including 884 foreign) postgraduate students, spread over 25 Schools of study. The University also has 16 research institutes and centres.

In its research activities, USM has increasingly adopted a thematic and inter-disciplinary approach, in order to optimise the value of its modern laboratory facilities and rich scientific talent. The University is fully aware that it is through the coming together of researchers from different scientific backgrounds, and hence the integration of different orientations and methodologies, that science has made many of its remarkable advances in recent years. Every encouragement is therefore given to collaboration across School boundaries in the conduct of research. Some of the crossdisciplinary research areas in which the University has proud achievements to report are outlined here. These and other areas are given full coverage in a recently produced six-volume publication that may be obtained by writing to Penerbit USM (penerbitusm@notes.usm.my).

USM has extensive research links with universities in other parts of the world. A separate commercial arm, USAINS Holding, has been established to manage relations with industry.

\section{Medical Biotechnology}

Medical Biotechnology is the application of molecular biology techniques in biomedical investigations and comprises both fundamental and applied research. This is a multi-disciplinary research cluster with scientists from the Institute for Research in Molecular Medicine and the Schools of Health Sciences, Medical Sciences, Biological Sciences and Dentistry.

The development of diagnostic tests for infectious diseases is one of the major strengths, based on research in typhoid, filariasis, tuberculosis, cholera, dysentery, campylobacteriosis, human pappilomavirus and Epstein-Barr virus. Five diagnostic kits have now been commercialised. The development of vaccines for tropical diseases such as tuberculosis, malaria and cholera is another important area of emphasis. Two cholera vaccine candidates have successfully been produced.

Fundamental research includes investigations of gene interaction and gene regulation, and molecular mechanisms in the modulation of PPAR $\gamma$ gene expression in immune and cancer cells. Understanding the molecular biology and genetic variability of human drug metabolism enzymes is the focus of the pharmacogenetics research group. Other promising areas of focus are structural biology and modelling, biomaterials and tissue engineering.

\section{Knowledge Processing and Management}

Knowledge management is the cycle of processes that covers the identification, acquisition, organisation, sharing, dissemination, adaptation and application of factually-rich explicit knowledge and experience-rich tacit knowledge towards improving the value of an organisation's products and services. $\mathrm{R} \& \mathrm{D}$ on knowledge management at USM focuses on the underlying science and its applications vis-à-vis knowledge as a computationally tractable object that can be studied, used and manipulated. USM is particularly strong in knowledge acquisition, drawing from techniques in natural language processing for transforming text to knowledge and from techniques in image processing for transforming images to knowledge. Artificial intelligence methods are used in knowledge organisation, adaptation and application, while technologies in computer networks are used for dissemination and, together with grid computing, for enhancing efficiency in knowledge processing in general. Applications of knowledge management at USM include tacit knowledge acquisition and explication in medicine and healthcare and 3D image rendering for use in surgery. Knowledge organisation techniques are used in a wide range of domains, from protein structures in bioinformatics, through enterprise knowledge ontologies in business, to landslide modelling in natural disaster mitigation.

\section{Environmental Studies}

Malaysia is recognised as one of the few remaining biodiversity hotspots in the world and this places USM in the forefront for the cataloguing of species and ecological research especially in wetlands and riverine (through conservation, restoration and rehabilitation studies) and forest ecosystems. USM has long been one of Malaysia's key centres for mangrove ecosystem research. Its extensive research output has enabled it to influence national policies on sustainable development. For instance, USM manages a 900 odd hectare island as a model for education and conservation. Reef studies, always a strong thrust at USM because of the long coastline, have been expanded to research and documentation of Malaysian oceanic and outer island biodiversity. More recently, USM experts have voyaged to Antarctica and taken part in research in areas such as the 
